\title{
Metastatic Tumor Sample
}

National Cancer Institute

\section{Source}

National Cancer Institute. Metastatic Tumor Sample. NCI Thesaurus. Code C156440.

A biospecimen derived from a metastatic tumor. 